\title{
Electricity Generation Performance of Microbial Fuel Cell Embedded in Anaerobic-Anoxic-0xic Wastewater Treatment Process
}

\author{
Bowei Li 1,2,3*, Wenbo Dong1,2,3*, Bojie Liu 1,2,3, Beizhen Xie',2,3\#, Hong Liu',2,3\# \\ ${ }^{1}$ School of Biological Science and Medical Engineering, Beihang University, Beijing, China \\ ${ }^{2}$ Institution of Environmental Biology and Life Support Technology, Beihang University, Beijing, China \\ ${ }^{3}$ International Joint Research Center of Aerospace Biotechnology \& Medical Engineering, Beihang University, \\ Beijing, China \\ Email: Ibwbuaa@163.com, "xiebeizhen@buaa.edu.cn, "ㄴH64@buaa.edu.cn
}

Received 24 July 2015; accepted 10 September 2015; published 17 September 2015

\begin{abstract}
Microbial fuel cell (MFC) embedded in anaerobic-anoxic-oxic $\left(A^{2} / 0\right)$ process has positive effects on wastewater treatment, which can enhance the efficiencies of pollutants' removal, along with electricity production. But the electricity generation performance and its optimization of MFC embedded in $A^{2} O$ process still needs to be further investigated. In this study, in order to optimize the contaminants removal and electricity production of the MFC- $A^{2} / 0$ reactor, a lab-scale corridor-style MFC- $\mathrm{A}^{2} / 0$ reactor, which could simulate the practical $\mathrm{A}^{2} / 0$ biological reactor better, was designed and operated. The removal efficiencies of chemical oxygen demand, total nitrogen and total phosphorus were continuously monitored so as the electricity generation. In addition, the influences of the structural parameters' changes of MFC on the output voltage, including electrode material, the directly connected area and the distance between electrodes, were also studied. The results elucidated that the effluent quality of $A^{2} / 0$ reactor could be improved when MFC was embedded, and all the investigated structural factors were closely related to the electricity generation performance of MFC to some extent.
\end{abstract}

\section{Keywords}

Microbial Fuel Cell, Anaerobic-Anoxic-Oxic, MFC-A ${ }^{2} / 0$ Reactor, Directly Connected Area, The Distance between Electrodes

\section{Introduction}

The anaerobic-anoxic-oxic $\left(\mathrm{A}^{2} / \mathrm{O}\right)$ process is a common wastewater treatment method because it can remove the

*Both authors contribute equally to this work.

${ }^{\#}$ Corresponding authors.

How to cite this paper: Li, B.W., Dong, W.B., Liu, B.J., Xie, B.Z. and Liu, H. (2015) Electricity Generation Performance of Microbial Fuel Cell Embedded in Anaerobic-Anoxic-Oxic Wastewater Treatment Process. Journal of Biosciences and Medicines, 3, 32-37. http://dx.doi.org/10.4236/jbm.2015.39005 
nitrogen and phosphorus at the same time [1]. The microbial fuel cell (MFC) is a novel technology and has the inestimable development potential in the energy and environment field. It utilizes microorganisms as catalyst to turn the chemical energy in organic matter into electricity directly, so that it can generate electricity and purify organic wastewater simultaneously [2]-[4].

Electrodes producing and consuming electrons have a great influence on electricity generation performance of MFC. MFC's cathode is a place where the reaction of electron and its acceptor occurs. The oxygen usually acts as the electron acceptor, reacting with electrons and protons to form water, but it needs to use Pt as the catalyst which causes a higher cost in this way. If the microorganisms are used as catalyst in cathodes, named bio-cathodes, we would solve the above problem. Moreover, compared with abiotic cathodes, the bio-cathode MFCs possess the following advantages: the cost of construction and operation of MFC may be lowered. Metal catalysts or artificial electron mediators could be made superfluous in MFCs with bio-cathodes, because microorganisms can function as catalysts to assist the electron transfer. The microbial metabolism in bio-cathodes may beutilized to produce useful products or remove unwanted compounds [5]. Gregory et al. found that $\mathrm{NO}_{3}^{-}$ could act as the sole electron accepter in a bio-cathode MFCs [6]. Virdis et al. were successfully established MFCs to simultaneously remove carbon and nitrogen [7].

Currently, eutrophication is one of the focal issues of social concern. Nitrogen, phosphorus and other elements in excess are important factors that lead to water pollution. Based on characteristics of biological denitrification cathode, the bio-cathode MFCs applied in the wastewater-treatment process are expected to improve the nitrogen and phosphorus removal efficiency. In previous study, we creatively proposed to embed an MFC in $\mathrm{A}^{2} / \mathrm{O}$ process. The anaerobic tank acted as the anode chamber of the MFC, while the anoxic tank was the cathode chamber. The results confirmed the feasibility that an MFC embedded $\mathrm{A}^{2} / \mathrm{O}$ process could strengthen the removal efficiency of nitrogen and phosphorus [8]. But because of the limitations of the structure resulting in high internal resistance and low coulomb efficiency, the MFC electricity production was less than ideal performance.

In this research, we designed and built a lab-scale corridor-style MFC-A ${ }^{2} / \mathrm{O}$ reactor in order to optimize its pollutant removal and electricity generation. The removal efficiencies of chemical oxygen demand (COD), total nitrogen (TN) and total phosphorus (TP) of $\mathrm{A}^{2} / \mathrm{O}$ bioreactor before and after embedding MFC were compared, and the output voltage of the embedded MFC was also monitored. By changing the structure parameters of the MFC- $\mathrm{A}^{2} / \mathrm{O}$ reactor, including electrode material, the directly connected area and the distance between electrodes, the relevant changes of the average output voltage were investigated and the better structural parameters were discussed accordingly.

\section{Experimental}

\subsection{Reactor Construction}

Two sets of lab-scale corridor-style MFC-A ${ }^{2} / O$ reactors in parallel running were set up, labeled A and $\mathrm{B}$. The components of two identical reactors mainly including: sewage tank, MFC- $\mathrm{A}^{2} / \mathrm{O}$ bioreactor, secondary settling tank, sludge storage tank. And three of them were made of plexiglass.

MFC- $\mathrm{A}^{2} / \mathrm{O}$ bioreactor was mainly composed of anaerobic zone, anoxic zone and aerobic zone. In addition, there were three baffles among them and a gap located at the bottom of anoxic zone, so that the wastewater can flow into the oxic zone. In front of the anaerobic zone, there were two inlets. At end of the oxiczone, there were two outlets containing effluent and reflux. We installed a card slot between anaerobic and anoxic zone, and the projected area could be adjusted by adding baffles. The sewage and sludge were thoroughly mixed by magnetic stirrers, which were actuated by arotated magnet module driven by a DC electric motor.

\subsection{Artificial Sewage and Activated Sludge}

Two sets of MFC-A $\mathrm{A}^{2} \mathrm{O}$ reactors (A and B) used artificial sewage to start up, and were all inoculated with residual sludge taken from a Beijing sewage factory. The artificial wastewater contains (per liter) [9]: $0.02 \mathrm{~g}$ starch, 0.19 g acetic acid, 0.158 g peptone, 0.04 g beef extract, $0.0347 \mathrm{~g} \mathrm{NH}_{4} \mathrm{Cl}, 0.284 \mathrm{~g}\left(\mathrm{NH}_{4}\right)_{2} \mathrm{SO}_{4}, 0.06 \mathrm{~g} \mathrm{Na}_{2} \mathrm{CO}_{3}$, $0.0293 \mathrm{~g} \mathrm{KH}_{2} \mathrm{PO}_{4}$. All chemicals were of analytical grade and used as received, and all aqueous solutions were prepared with purified water.

The sewage and reflux sludge in a ratio of $1: 1$ by peristaltic pumped into tank, both the inflow rate were about 
$10 \mathrm{~mL} / \mathrm{min}$ as well as the inner recycling flow rate. HRT was kept at $16.7 \mathrm{~h}$. The reactor was maintained at room temperature. After adding the sludge, we adopted the way of continuous water running. The initial mixed liquor suspended solids (MLSS) was $2400 \mathrm{mg} / \mathrm{L}$. In the whole experiment, the MLSS was maintained at 2000 - 3000 $\mathrm{mg} / \mathrm{L}$ by discharging the excess sludge from the returned sludge tank.

\subsection{Start-Up and Operation Stage}

In the start-up stage, two devices were the conventional $A^{2} / O$ reactor which didn't embed the MFC. When the pollutant removal of the reactor became stable by continuously monitoring the concentration of the COD, TN and TP, the devices entered into the operational stage that MFCs were embedded to construct the MFC- $\mathrm{A}^{2} / \mathrm{O}$ reactor. The anodes of two devices were made of carbon brushes (diameter $10 \mathrm{~mm}$, length $300 \mathrm{~mm}$, TC12K35, Taiwan Formosa) in anaerobic zone. Adding carbon cloth (20 mm $\times 20 \mathrm{~mm} \times 2$, HP330 Shanghai Heseng, China, labeled group A) and brushes (diameter $10 \mathrm{~mm}$, length $300 \mathrm{~mm}, \mathrm{TC12K35}$, Taiwan Formosa, labeled group B) respectively to the anoxic zone. The electrodes were both pre-treated with ammonia and connected to a closed loop through the external wire and resistance box (0 - $99999.9 \Omega$, ZX21, Shanghai Guoguang, China), to form a complete MFC- $\mathrm{A}^{2} / \mathrm{O}$ reactor.

\subsection{Analysis and Calculations}

Total nitrogen (TN) was measured by an alkaline potassiumpersulfate digestion-UV spectrophotometric method, and total phosphorus (TP), the chemical oxygen demand (COD), and MLSS were measured following standard methods [10].

The output voltage of the MFC was monitored every $10 \mathrm{~s}$ bydata acquisition system (USB1608FS, Measurement Computing Corporation, USA; Tracer DAQ pro software).

The polarization curve was obtained by changing the circuit external resistance when the MFC achieved steady state.

\section{Results and Discussion}

\subsection{The Removal Efficiency}

After nearly a month of debugging time, the effluent of reactors achieved steady state and the removal efficiencies of pollutant also reached a certain level. In the start-upstage, the average removal efficiencies of COD, TN and TP were shown in Table 1. The data indicated that the conditions of were relatively stable and demonstrated the successful startup for two sets of devices.

The reactors entered the operation stage after the successful startup, and two kinds of electrodes were installed correspondingly in the anaerobic and anoxic zone and thus to set up complete MFC- $\mathrm{A}^{2} / \mathrm{O}$ reactors. The average removal efficiencies of pollutants were shown in Table 1.

Comparing start-up with operation stage, we could see the influence of embedded MFC on effluent quality in $\mathrm{A}^{2} / \mathrm{O}$ process. Before embedding the MFC, the COD removal efficiencies of group A and B were not very stable, ranging from $80 \%$ to $97 \%$. After 27 days, the removal of A and B were $95.35 \%$ and $94.80 \%$, respectively. At 28th, two groups were embedded the MFC, and then the removal efficiencies of A and B were $97.21 \%$ and 96.10\%. In Table 1, we found that, before embedding the MFC in A and B, the average removal efficiencies of COD were $91.95 \% \pm 6.08 \%$ and $91.51 \% \pm 4.40 \%$. After equipped with electrode, the average removal efficiencies of COD were rose up to $94.96 \% \pm 2.56 \%$ and $94.33 \% \pm 2.15 \%$, respectively. The average removal efficiencies

Table 1. The average removal efficiency.

\begin{tabular}{cccr}
\hline & COD/R ${ }^{*}(\%)$ & TN/R ${ }^{*}(\%)$ & TP/R $(\%)$ \\
$\mathrm{A}^{1}$ & $91.95 \pm 6.08$ & $80.23 \pm 12.51$ & $45.29 \pm 8.49$ \\
$\mathrm{~A}^{2}$ & $94.96 \pm 2.56$ & $87.69 \pm 9.41$ & $60.51 \pm 11.45$ \\
$\mathrm{~B}^{1}$ & $91.51 \pm 4.40$ & $88.13 \pm 9.87$ & $45.48 \pm 8.30$ \\
$\mathrm{~B}^{2}$ & $94.33 \pm 2.15$ & $86.73 \pm 9.70$ & $57.00 \pm 11.90$ \\
\hline
\end{tabular}

$\mathrm{R}^{*}$ : The average removal efficiency; ${ }^{1}$ - start-up stage; ${ }^{2}$ - operating stage. 
increased about three percentages, and that became more stable. It was mainly due to the embedded MFC used anaerobic zone as the anode chamber and a part of organic matters in swage could beconsumed by electricigens to generate electricity, thus to strengthen the COD removal efficiencies [11].

Before 15 days, the TN removal efficiencies of two groups were fluctuant, which from $60 \%$ to $90 \%$. After 15 days, the efficiencies gradually became stable and improved. At 27th, the TN removal efficiencies of A and B were $90.30 \%$ and $91.95 \%$, respectively. To embed the MFC in 28 days, the efficiencies increased to $96.50 \%$ and $97.19 \%$, respectively. Compared to the average removal efficiency, we found that two reactors were only $80.23 \% \pm 12.51 \%$ and $88.13 \% \pm 9.87 \%$ before embedding MFC. After embedding MFC, the efficiencies of A and $\mathrm{B}$ changed to $87.69 \% \pm 9.41 \%$ and $86.73 \% \pm 9.70 \%$, and also the TN removal efficiencies were stable at the higher level for a period of time. It was shown that embedding MFC in $\mathrm{A}^{2} / \mathrm{O}$ had certain reinforcement on denitrification. Analysis was that the denitrifying bacteria of bio-cathode could strengthen the denitrification process, so as to enhance the whole reactor denitrification efficiency [12]. Because of the changes in electrode operation parameters such as the conditions and agingsludge at end of the trial, the reactor denitrification performance would decrease as a whole.

From Table 1, we concluded that the TP removal efficiencies of two reactors were relatively low. The analysis may be associated with a higher TP concentration of the inflow sewage and the microbial community structure of the sludge. Because of the slow growth of the activated sludge, we didn't discharge regularly excess sludge in order to maintain sufficient concentration of sludge in the reactor. It also might be one of the reasons that phosphorus removal efficiencies were not high. Before embedding MFC, we found that TP removal efficiencies were less than $50 \%$ on average and showed a downward trend in detecting the quality of the effluent. While the TP removal efficiencies had been on an upward trend after embedding MFCs, the average removal efficiencies were about $60 \%$. We also found phosphorus removal efficiencies had improved when MFC embedded in $\mathrm{A}^{2} / \mathrm{O}$ process. The reason was partly because the bio-cathodes could ease competition for carbon between phosphorus and denitrification in a certain extent, and were helpful for anaerobic phosphorus' release [13]. What's more, the electrode materials of reactor could be seen as the larger surface area of the filler which provided a better living environment for PAOs, thus to reinforce the phosphorus removal process [14].

\subsection{Structural Parameters'}

\subsubsection{Electrode Material}

The two groups of MFC- $\mathrm{A}^{2} / \mathrm{O}$ reactors were operated in continuous flow under the same conditions. Group A used the carbon cloth as the cathode, but otherwise the group B used the carbon brush. By comparing the output voltage of two groups, we observed the effect of different electrode materials on generation performance in MFC (Figure 1).

Compared to electricity generation situation of A and B after normal electricity production in $19 \mathrm{~h}(34 \mathrm{~h}-53$ h), we found that the initial stage of group A could reach $0.32 \mathrm{~V}$, which was much higher than group B, $0.12 \mathrm{~V}$. The output voltage of group A was gradually declining, while there wasn't shown big fluctuations in group B. When the group A tended to be stable, the voltage was basically the same with group B.

\subsubsection{The Directly Connected Area}

After running stability, weadded a baffle between the anaerobic and anoxic zone, respectively. To make the directly connected area (projected area) of MFC from $3500 \mathrm{~mm}^{2}$ to $1750 \mathrm{~mm}^{2}$, we studied its effects on production performance. Before adding the baffle, the average output voltage of MFC in A and B devices were $0.4183 \pm$ $0.08935 \mathrm{~V}$ and $0.1137 \pm 0.03985 \mathrm{~V}$. After adding the baffle, the output voltage of A and B were $0.2014 \pm$ $0.09911 \mathrm{~V}$ and $0.06894 \pm 0.06776 \mathrm{~V}$, respectively. The situation of adding the baffle in two reactors was shown in Figure 2(a).

\subsubsection{The Distance between Electrodes}

At the beginning of the experiment, the distance between cathode and anode of MFC- $\mathrm{A}^{2} / \mathrm{O}$ was about $140 \mathrm{~mm}$, then the gap widened to $260 \mathrm{~mm}$, and we monitored the output voltage of MFC by data acquisition system. The results were shown in Figure 2(b). When the distance was $140 \mathrm{~mm}$, the average output voltages of the MFC in $\mathrm{A}$ and $\mathrm{B}$ were $0.1092 \pm 0.06318 \mathrm{~V}$ and $0.1080 \pm 0.06225 \mathrm{~V}$, respectively. When the distance increased to 260 $\mathrm{mm}$, the output voltages decreased severely, were $0.04706 \pm 0.02807 \mathrm{~V}(\mathrm{~A})$ and $0.02142 \pm 0.008455 \mathrm{~V}$ (B). 


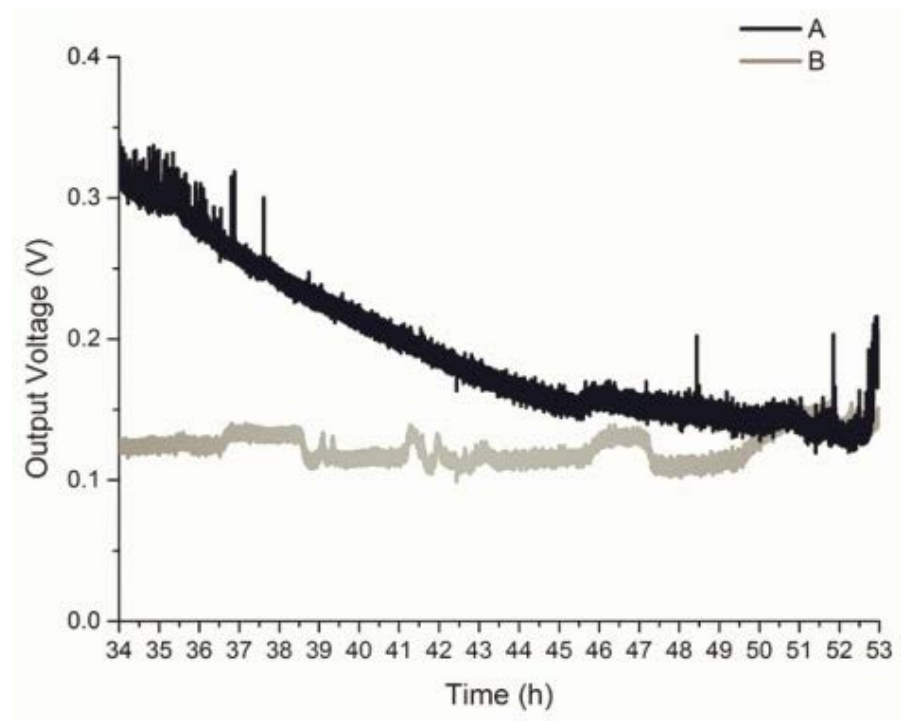

Figure 1. Response of output voltage in carbon cloth (A) and carbon brush (B) at the same stage.

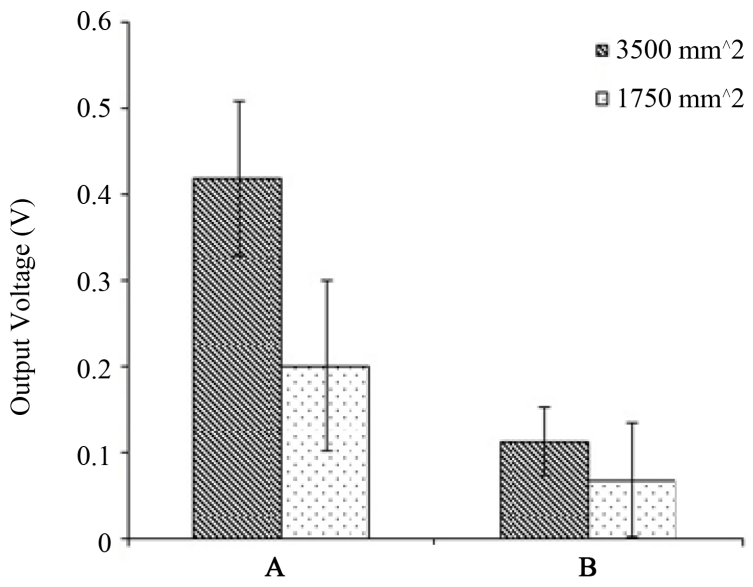

(a)

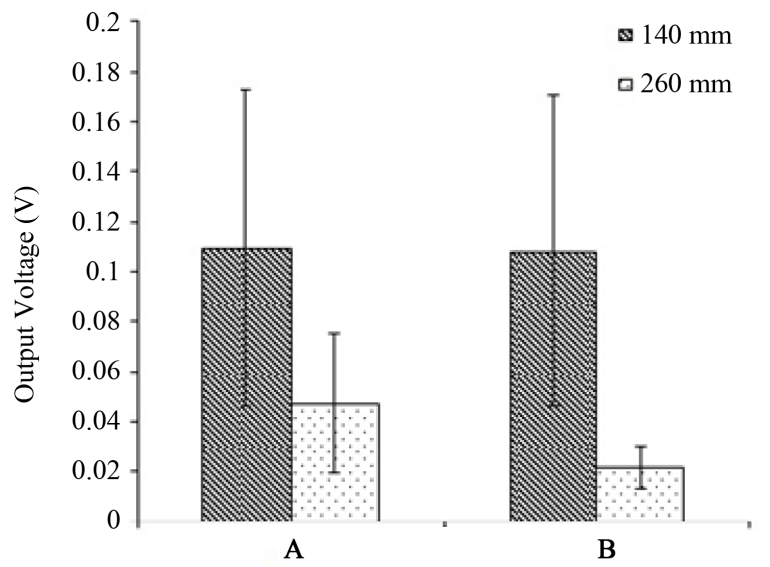

(b)

Figure 2. The output voltage of MFC in different projected areas. (a) and different distances (b). Vertical bars are means \pm S.D.

\section{Conclusion}

In this research, the structure of the experimental device has carried on the comprehensive optimization and improvement. By successfully started and ran a new-designed MFC- ${ }^{2} / O$ reactor, we demonstrated that embedding MFC in $\mathrm{A}^{2} / \mathrm{O}$ sewage treatment process could further improve the removal efficiencies of the COD, TN, TP. On the basis of the experimental studies, we found that the structure of the MFC- $\mathrm{A}^{2} / \mathrm{O}$ reactor parameters (change of electrode materials, the effective projection area, electrode spacing) could affect the reactor operation condition. The connections among them can help us to optimize the reactor, and to achieve the optimal treatment effect or electricity generation performance, which will have a certain guiding role for the actual application.

\section{Acknowledgements}

This work was financially supported by grants from International Science-Technology Cooperation Program of China (2013DFR60250), National Nature Science Foundation of China (31200098), the Specialized Research Fund for the Doctoral Program of Higher Education of China (20131102120039), the Funds for Central University Basic Scientific Research. 


\section{References}

[1] Mulkerrins, D., Jordan, C., McMahon, S. and Colleran, E. (2000) Evaluation of the Parameters Affecting Nitrogen and Phosphorus Removal Inanaerobic/Anoxic/Oxic(A/A/O) Biological Nutrient Removal Systems. Journal of Chemical Technology and Biotechnology, 75, 261-268. http://dx.doi.org/10.1002/(SICI)1097-4660(200004)75:4<261::AID-JCTB213>3.0.CO;2-X

[2] Logan, B.E. (2008) Microbial Fuel Cell. Wiley-Interscience.

[3] Lovley, D.R. (2006) Microbial Fuel Cells: Novel Microbial Physiologies and Engineering Approaches. Current Opinion in Biotechnology, 17, 327-332. http://dx.doi.org/10.1016/j.copbio.2006.04.006

[4] Rabaey, K. and Verstraete, W. (2005) Microbial Fuel Cells: Novel Biotechnology for Energy Generation. Trends in Biotechnology, 23, 291-298. http://dx.doi.org/10.1016/j.tibtech.2005.04.008

[5] He, Z. and Angenent, L.T. (2006) Application of Bacterial Biocathodes in Microbial Fuel Cells. Electroanalysis, 18, 19-20. http://dx.doi.org/10.1002/elan.200603628

[6] Gregory, K.B., Bond, D.R. and Lovley, D.R. (2004) Graphite Electrodes as Electrondonors for Anaerobic Respiration. Environmental Microbiology, 6, 596-604. http://dx.doi.org/10.1111/j.1462-2920.2004.00593.x

[7] Virdis, B., Rabaey, K., Yuan, Z. and Keller, J. (2008) Microbial Fuel Cells for Simultaneous Carbon and Nitrogen Removal. Water Research, 42, 3013-3024. http://dx.doi.org/10.1016/j.watres.2008.03.017

[8] Xie, B., Dong, W., Liu, B. and Liu, H. (2014) Enhancement of Pollutants Removal from Real Sewage by Embedding Microbial Fuel Cell in Anaerobic-Anoxic-Oxic Wastewater Treatment Process. Journal of Chemical Technology and Biotechnology, 89, 448-454. http://dx.doi.org/10.1002/jctb.4138

[9] APHA, AWWA and WPCF (1998) Standard Method for Examination of Water and Wastewater. 20th Edition, American Public Health Association, Washington DC.

[10] Logan, B.E., Hamelers, B., Rozendal, R., Schroder, U., Keller J., Freguia, S., Aelterman, P., Verstraete, W. and Rabaey, A.K. (2006) Microbial Fuel Cells: Methodology and Technology. Environmental Science \& Technology, 40, 51815192. http://dx.doi.org/10.1021/es0605016

[11] Lovley, D.R. (2008) The Microbe Electric: Conversion of Organic Matter to Electricity. Current Opinion in Biotechnology, 19, 564-571. http://dx.doi.org/10.1016/j.copbio.2008.10.005

[12] Virdis, B., Read, S.T., Rabaey, K., Rozendal, R.A., Yuan, Z. and Keller, J. (2011) Biofilm Stratification during Simultaneous Nitrification and Denitrification (SND) at a Biocathode. Bioresource Technology, 102, 334-341. http://dx.doi.org/10.1016/j.biortech.2010.06.155

[13] Kuba, T. and Van Loosdrecht, M.C.M. (1996) Phosphorus and Nitrogen Removal with Minimal COD Requirement by Integration of Denitrifying 1'Dephosphatation and Nitrification in a Two-Sludge System. Water Research, 30, 17021710. http://dx.doi.org/10.1016/0043-1354(96)00050-4

[14] Zhang, X., Cheng, S., Liang, P., Huang, X. and Logan, B.E. (2010) The Use of Nylon and Glass Fiber Filter Separators with Different Pore Sizes in Air-Cathode Single-Chamber Microbial Fuel Cells. Energy \& Environmental Science, 3, 659-666. http://dx.doi.org/10.1039/b927151a 